\title{
The Alveolar Epithelium and Pulmonary Fibrosis
}

\author{
Huiping $\mathrm{Li}^{*}$
}

Department of Respiratory Diseases, Shanghai Pulmonary Hospital, Tongji University, Shanghai, China

\begin{abstract}
Idiopathic interstitial pneumonias (IIPs) are a heterogeneous group of diffuse pulmonary parenchymal diseases that are comprised of seven distinct clinical and pathological entities. Idiopathic pulmonary fibrosis (IPF) and cryptogenic organizing pneumonia (COP) represent two of the most prevalent members of the disease group with major differences in their pathogenesis, clinical course and prognosis. IPF is a refractory and lethal IIP characterized by fibroblast proliferation, deposition of extracellular matrix (ECM) and progressive lung scarring. The incidence of IPF is estimated at 15 to 40 cases per 100,000 per year, and the mean survival from the time of diagnosis is 3 to 5 years regardless of treatment. While its pathogenesis is incompletely understood, the currently accepted paradigm proposes that injury of the alveolar epithelium is followed by a burst of pro-inflammatory and fibroproliferative mediators that invoke responses associated with dysregulated repair of the damaged alveolar epithelium. Recently, there have been studies suggesting that the activation of the alveolar epithelial cells (AECs) may play an active role in the pathogenesis of pulmonary fibrosis. Here, we review the advances in recent studies on the role of the alveolar epithelium in pulmonary fibrosis.
\end{abstract}

\section{AECS: A BRIEF OVERVIEW OF STRUCTURE AND PHYSIOLOGICAL FUNCTIONS}

Two types of AECs populate the alveolar epithelium in normal adult lungs, alveolar epithelial type I (AT I) and alveolar epithelial type II (AT II) cells. AT I pneumocytes comprise $40 \%$ of the AECs and cover $90 \%$ of the internal surface area of the lung. AT I cells are highly attenuated and form an interface with pulmonary capillaries that are intimately involved in gas exchange. These cells also take part in peptide and amino acid transportation across the lung by pinocytosis and transporter-mediated transport [1]. Recently, AT I cells have been shown to be also important in the transportation of water and sodium across the lung $[2,3]$.

AT II cells, on the other hand, AT II cells make up 16\% of the parenchymal cells in the lung and account for only 5\% of the alveolar surface. These cells are cuboidal cells that are situated between AT I cells and they contain characteristic lamellar bodies and apical microvilli. AT II cells synthesize, store and secrete the pulmonary surfactant (PS), which consists of lipids and their associated proteins and whose function is to reduce the surface tension of the lung alveolus and prevent it from collapse or overdistension with respiration. AT II cells also regulate alveolar fluid balance in normal lungs and during the resolution of pulmonary edema [4] and the pathogenesis of acute lung injury with pulmonary edema is associated with an insufficient number of AT II cells and transportation of water into the lung alveolus. Recently, AT II cells have been shown to synthesize and secrete immunomodulatory proteins important for host defense, including surfactant proteins A (SP-A) and D (SP-D) [5]. SP-A can combine with lipid A in the lipopolysaccharide on the surface of bacterium and it also regulates the activities of

*Address correspondence to this author at the Department of Respiratory Diseases, Shanghai Pulmonary Hospital, Tongji University, 507 Zhengmin road, Shanghai, 200433, China; Tel: 86-21-65115006-2103; Fax: 86-2155663289; E-mail: lihuiping1958@yahoo.com.cn pulmonary alveolar macrophages and modulates phagocytosis [6].

It has been long assumed that AT I cells are terminally differentiated cells and cannot self-renew or self-repair when they are injured. AT II cells, on the other hand, are capable of self-renewal and differentiation and may function as stem cells to regenerate AT I cells [7, 8]. Damaged AT I cells may also be replaced by bone marrow derived stem cells that can differentiate into AT I cells [9], suggesting that alveolar progenitor cells may not only be derived from local sources of self-renewing progenitor cells but also from extrapulmonary reparative progenitor subpopulations. This concept of exogenous progenitor cells for replenishing damaged AT I cells is also supported by the findings of Abe et al. who demonstrated that bone marrow derived stem cells could differentiate into AT I cells [10].

\section{AT I CELLS ARE INVOLVED IN PULMONARY FIBROSIS}

The lung is an organ situated in the body that provides an interface between the host's internal milieu and the external environment. AT I cells, which cover most of the surface of the lung, form tight intercellular junctions and deny access of fibrogenic particles like silica to interstitial macrophages and fibroblasts in the lung. Injury of the AECs exposes the ECM to fibrogenic particles and annuls the protection of the pulmonary integrity by AT I cells. It also initiates the process of hemorrhage and extravasation of plasma into the lung tissue, resulting in the activation of both the intrinsic and extrinsic coagulation pathway and subsequent fibrin deposition. AT I cells, fibroblasts and alveolar macrophages express tissue factors, urokinase type plasminogen activators (uPA) and plasminogen activator inhibitors (PAI), and regulate the activity of fibrinolysis and the clearance of fibrin in the lung alveolus [11]. Injury of the AECs compromises the ability of AT I cells to clear redundant fibrin in the lung alveolus and impairs their capability to endocytoze fibrin deposits. 
The amount of tissue factor, which binds to and activates factor VII and initiates the activation of downstream coagulation cascade, increases during lung injury, resulting in enhanced coagulation in the lung. There is also disequilibrium between UPA and PAI in the lung. UPA and its receptor, uPAR, combine to increase fibrinolysis. Additionally, the activities of UPA in AT I cells have been shown to be regulated at the posttranscriptional level. Shetty et al. found that a urokinase mRNA binding protein binds to a 66 nucleotide region in the mRNA and destabilize it [12], suggesting that the level of uPA is tightly regulated in the normal lung. Platelet activation and degranulation also occur during coagulation, leading to the release of cytokines that can activate leukocytes, endothelial cells, macrophages, fibroblasts and AECs. Recent evidence also suggests that efficient repair of damaged alveolar epithelium depends on the attainment of a fibrinolytic optimum in the pulmonary microenvironment [13]. Therefore, dysregulated coagulation and fibrinolysis upon injury to the AECs and compromised repair capability of AT I cells may lead to multiple cycles of coagulation and fibrinolysis, which may aggravate alveolar injury and induce pulmonary fibrosis.

\section{THE ROLE OF AT II CELLS IN PULMONARY FIBROSIS}

Unlike AT I cells, which are terminally differentiated and incapable of self-renewal or repair, AT II cells are able to self-renew, repopulate and repair damaged alveolar epithelium [14]. AT II cells have been shown to interact with fibroblasts and ECM in the lung $[15,16]$. Their foot processes pass through the basement membrane and are in contact with fibroblasts in the pulmonary interstitium, an observation that has been confirmed by electron microscopy, suggesting that direct contact between lung fibroblasts and AT II cells may serve as a conduit for signal conduction among the cells, thereby coordinating the activities of AT II cells and fibroblasts [17]. When the alveolar epithelium is damaged, AT II cells start proliferating and transdifferentiate into AT I cells to reestablish a functional alveolar epithelium. Fibroblasts that are in contact with proliferating AT II cells also become activated and start proliferating to participate in the repair process. Unrestrained proliferation of fibroblasts in the lung interstitium following lung injury would contribute to the development of pulmonary fibrosis.

The basement membrane is a complex structure that contains type IV collagen, laminin, fibronectin, entactin and heparin sulfate-chondroitin proteoglycans and it plays a dynamic role in maintaining the integrity and differentiation of the alveolar epithelium. AT II cells synthesize some of the essential components of the basement membrane such as fibronectin, laminin and type IV collagen that are important for maintaining the integrity of the alveolar epithelium and for regulating the migration, differentiation and adhesion of fibroblasts and other types of cells. Injury of AT II cells compromises their production of the components of the basement membrane, resulting in the loss of the integrity of the basement membrane. Fibroblasts and myofibroblasts can migrate into the alveolar space through the partially disrupted and denuded basement membrane, which promotes the development of pulmonary fibrosis.

\section{AT II CELLS AND THE INFLAMMATORY RE- ACTION}

Lung injury that triggers pulmonary fibrosis is followed by inflammatory events where damaged alveolar epithelium and other resident cells release inflammatory mediators that promote the recruitment of inflammatory cells. Pulmonary fibrosis is a progressive and irreversible disease process and is believed to be due to repeated inflammations, resulting in an excessive proliferation of fibroblasts and deposition of ECM. Sime et al. used active TGF- $\beta$ transgene to induce lung fibrosis in rats and found that inflammation was present and peaked before maximal fibrosis [18]. SP-A, which is produced by AT II cells, promotes the alveolar macrophages to produce various inflammatory mediators and cytokines that reinforce the inflammatory reaction. Immunohistochemical studies further reveal that most of AT II cells express intercellular adhesion molecule-1 (ICAM-1) and a minority of them express integrin- $\beta_{1}$ subunit- $\alpha_{4}(C D 49 \alpha)$ and vitronectin receptor subunit- $\alpha_{5}$ (CD51) in normal lung. ICAM-1 binds to lymphocyte function-associated antigen-1 (LFA-1) on lymphocytes during lung injury to promote the inflammatory reaction by recruiting leucocytes into the lung interstitium [19]. CD44 isoforms are also expressed in AT II cells. Kasper and colleagues have shown that, in normal lung tissue, CD44s is expressed on the cell surface of epithelial cells, which, however, is located in the cytoplasm of epithelial cells in pulmonary fibrosis [20]. The CD44v variants, CD44v6 and CD44v9 and CD44s are located at the basolateral aspect of AT II cells, suggesting that these proteins may be involved in epithelial cells-fibroblast interaction during lung repair [21] CD44s also likely regulates the synthesis and degradation of ECM [22].

Cultured AT II cells and rat AT II cells exposed to silica expressed chemotactic factors for neutrophils such as macrophage inflammatory protein-2 (MIP-2), which recruit heterophile granulocytes that produce collagenase, elastase and other types of proteases, which can degrade ECM proteins $[23,24]$. AT II cells are the main site of metabolism for arachidonic acids in the lung, which causes the release of lipid mediators of inflammation such as leukotrienes (LT) and prostaglandins (PG). Injury to AT II cells in pulmonary fibrosis causes a massive release of prostaglandins $E_{2}$ $\left(\mathrm{PGE}_{2}\right)$, which leads to increased vascular permeability in the lung and, as a consequence, alveolar proteinosis. This pathological change in which large amounts of plasma proteins permeate the alveolar space is positively correlated with pulmonary fibrosis [25]. In addition, AT II cells also synthesize interferon-like proteins, complements $\mathrm{C}_{2}, \mathrm{C}_{3}, \mathrm{C}_{4}, \mathrm{C}_{5}$ and factor $\mathrm{B}$, which are also involved in inflammatory reaction.

\section{GROWTH FACTORS AND LUNG FIBROSIS}

Growth factors like transforming growth factor $\beta$ (TGF$\beta)$ and insulin-like growth factor 1 (IGF-1) and others promote the proliferation of lung fibroblasts, induce chemotaxis of fibroblasts and regulate the synthesis of collagens, which may be associated with the development of pulmonary fibrosis. TGF- $\beta$ consists of a highly homologous group of multifunctional regulatory peptides that are differentially expressed and involved in the control of cell growth, differentiation, morphogenesis and ECM remodeling and is the most potent and efficacious cytokine in promoting fibrosis. TGF- 
$\beta 1$ promotes fibroblasts and AT II cells to synthesize ECM proteins such as collagen type I, III, IV and fibronectin. Sime et al. showed that TGF- $\beta$ transgeene promoted lung fibrosis in rats [18] and similar findings were also obtained in mice that overexpression of TGF- $\beta$ promoted lung fibrosis [26]. TGF- $\beta 1$ is upregulated in various human and experimental fibrotic diseases including pulmonary fibrosis [27], and inhibition of its bioactivity suppresses matrix production and could modulate the fibrotic process [28, 29], suggesting that TGF- $\beta 1$ may represent an ideal target for developing targeted therapies.

IPF is characterized by the proliferation of macrophages and AT II cells and deposition of ECM and immune complexes. These cells express increased mRNA and protein levels of platelet-derived growth factor (PDGF), IGF-1 and their corresponding receptors $[30,31]$. The release of PDGF, TGF- $\beta 1$, tumor necrosis factor (TNF)- $\alpha$ by these and other cells activate resident inflammatory cells that intensify both the inflammatory and fibrotic events in the lung. PDGF regulates TGF- $\beta 1$ and TNF- $\alpha$ and actively contributes to pulmonary fibrosis. Noticeably, increased expression of PDGF has been observed in IPF [32]. PDGF and IGF-1 induce the proliferation of fibroblasts and stimulate collagen synthesis. PDGF was shown to effectively induce the proliferation of fibroblasts at very low doses (pg to $\mathrm{ng} / \mathrm{ml}$ ) and was chemotactic for fibroblasts in vitro [33]. TNF- $\alpha$ saw its increased expression in AT II cells in lung specimens from patients with cryptogenic fibrosing alveolitis [34]. In addition, TGF- $\beta$ upregulated the levels of interleukin (IL)-1 and IL-8 in AT II cells from patients with pulmonary fibrosis and in vitro [35]. TNF- $\alpha$ and IL- 1 stimulate the production of collagen type I and III, and fibronectin [36, 37]. Sakai and colleagues detected the presence of hepatocyte growth factors (HGF) in bronchoalveolar lavage fluid from patients with IPF and showed that HGFs were produced by pulmonary macrophages and AT II cells [38]. HGF has been shown to inhibit the progression of bleomycin-induced pulmonary fibrosis in mice, which may be due to inhibition by HGF of TGF- $\beta$ signaling through induction of Smad-7, an inhibitor of TGF- $\beta$ signaling [39]. These findings taken together suggest that multiple cellular factors are involved in the process of lung fibrosis.

\section{EPITHELIAL CELL APOPTOSIS IS INVOLVED IN LUNG FIBROSIS}

The alveolar epithelium is not only the primary site of lung damage but also the primary site of a series of inflammatory events that are critical to the development of pulmonary fibrosis including the release of inflammatory mediators. Alterations in the structure and function of lung epithelial cells may affect the expression or production of important molecules that modulate the lung's response to injury. Epithelial cells in IPF secrete a number of molecules, such as growth factors and their receptors, proteases, surfactant proteins, adhesion molecules and ECM proteins that regulate the inflammatory and fibrotic response within the lung. Prominent injury of AECs is a characteristic feature of IPF. Although AT I pneumocytes comprise $40 \%$ of the AECl population and cover over $90 \%$ of the alveolar surface in the normal lung, they are markedly decreased in numbers in the area of severe inflammation following extensive injury and cell death in the lung tissue from patients with IPF. AT II cells are capable of self-renewal and repair and rapidly proliferate following epithelial cell injury. In the most severely damaged alveolar epithelium, the denuded basement membrane is covered by proliferating AT II cells, and there is a dearth of both AT I and II cells with massive infiltration by fibroblasts and myofibroblasts [40].

Recent findings in tissue specimens from patients with IPF revealed that AT II cells undergo severe endoplasmic stress and show evidence of apoptotic death [41, 42]. Bleomycin rapidly produces extensive DNA damage in the lung and electron microscopy shows the characteristic features of apoptosis in bronchiolar and alveolar epithelial cells [43], suggesting that DNA damage and apoptosis of epithelial cells may be associated with pulmonary fibrosis. DNA damage and apoptosis were also observed in bronchiolar and alveolar epithelial cells in IPF using an in situ DNA nick-end labeling method and electron microscopy [44-46]. DNA damage and apoptosis in lung epithelial cells have also been reported for acute lung injury and diffuse alveolar damage $[47,48]$. Increased expression of proapoptotic proteins and decreased expression of antiapoptotic proteins have also been observed in IPF $[49,50]$. One of the intracellular events required for apoptotic cell death in several systems, including the Fas-FasL pathway, is the activation of caspases. The tripeptide benzyloxycarbonyl-Val-Ala-Asp fluoromethylketone (Z-VAD.fmk), a broad-spectrum caspase inhibitor, inhibited the intracellular activation of caspase-like proteases in vivo, and protected mice against LPS-induced acute lung injury $[51,52]$. It also attenuated bleomycin-induced pulmonary fibrosis in mice $[53,54]$. Although the precise mechanisms whereby epithelial cell apoptosis leads to pulmonary fibrosis remain to be examined, epithelial cell apoptosis probably has an important role in the pathogenesis of lung injury and fibrosis (Fig. 1). Studies of human IPF show high rates of apoptosis and increased levels of pro-apoptosis markers in AECs; however, adjacent fibroblasts/myofibroblasts are relatively resistant to apoptosis $[49,55]$. The mechanisms of their resistance to apoptosis remain to be elucidated.

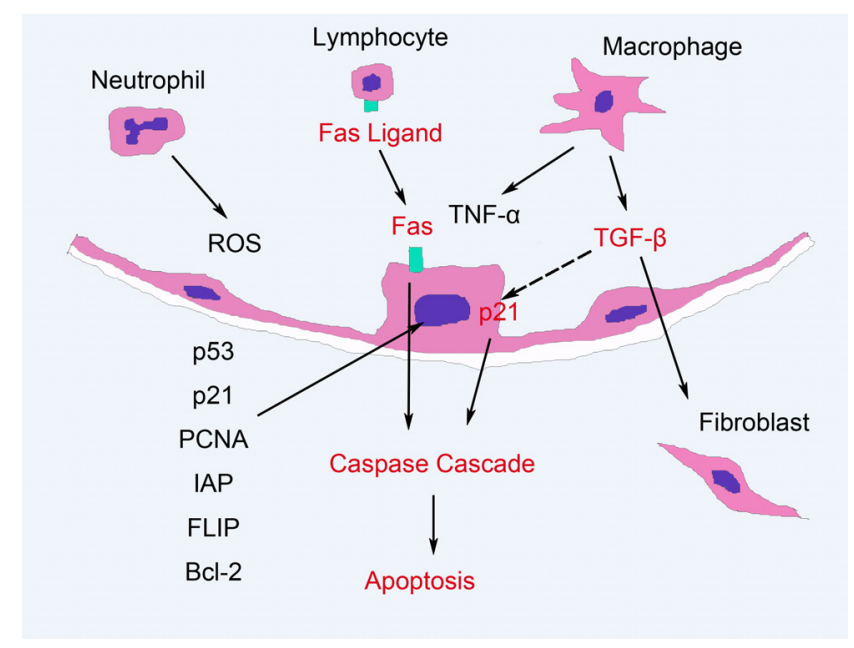

Fig. (1). Apoptosis of alveolar epithelial cells in idiopathic pulmonary fibrosis. 


\section{THE EPITHELIAL MESENCHYMAL TRANSITION AND LUNG FIBROSIS}

Although the exact mechanisms for the pathogenesis of pulmonary fibrosis remain unknown, the long prevailing inflammatory fibrosis hypothesis asserts that chronic inflammation plays an essential role in pulmonary fibrosis [56]. It holds the view that the loss of AT I pneumocytes and the proliferation of AT II cells are the results of lung injuries and the subsequent unrelenting inflammatory process, leading to the development of pulmonary fibrosis. However, many IPF patients show little evidence of ongoing inflammation, and treatment focused on inhibition of inflammation with steroids and/or immunosuppressive drugs has had little impact on the disease [57].

An alternative hypothesis has been proposed that IPF likely results from an aberrant activation of AVEs after injury that provoke the migration, proliferation, and abnormal activation of mesenchymal cells, leading to the exaggerated accumulation of ECM with an irreversible destruction of the pulmonary parenchyma [58-60]. Witschi et al. suggested that pulmonary fibrosis may result from impeded restoration of the damaged alveolar epithelium [61]. In IPF, the alveolar epithelium shows a marked loss of or damage to AT I cells and hyperplasia of AT II cells. Injury to the AECs and the denudement of the basement membrane initiates the attempt to restore the damaged alveolar epithelium by AV II cells, whose capacity to restore damaged AT I cells, however, is seriously compromised, leading to inadequate reepithelialization of the damaged alveolar epithelium and unregulated behaviors of fibroblasts/myofibroblasts. Earlier electron microscopic studies showed a loss of AECs and the presence of widely scattered loose aggregated interstitial fibroblasts [62, 63]. These so-called fibroblastic foci, which are characteristic features in the lung parenchyma of patients with IPF, comprise aggregates of mesenchymal cells that underlie sites of unresolved microscopic epithelial injury and which are associated with the progression of pulmonary fibrosis.

Several potential cellular sources of myofibroblasts in IPF have been suggested, including resident fibroblasts, circulating fibroblasts, and circulating progenitor cells. Recently, the possibility that AECs may transdifferentiate into fibroblasts/ myofibroblasts has gained attention [58, 64]. The epithelial mesenchymal transition, which occurs widely under both physiological and pathological conditions, is important for cellular differentiation by enabling the development of the mesoderm from the epithelium during development or a disease process. Willis and colleagues have shown that AECs may serve as a novel source of myofibroblasts in IPF through the epithelial mesenchymal transition under stimulation by TGF- $\beta[65,66]$ and this finding has also been shown by others $[67,68]$. The epithelial mesenchymal transition and the interaction between AECs and mesenchymal cells may play an important role in the pathogenesis of fibrosis (Fig. 2).

In summary, pulmonary fibrosis remains a devastating disease process whose mechanisms of pathogenesis remains to be elucidated. Existing knowledge suggests that there is interplay between multiple types of cells and diverse cellular factors. The AECs, which become activated by the disease process, may play dual roles in pulmonary fibrosis by participating in the repair process to restore the integrity of the
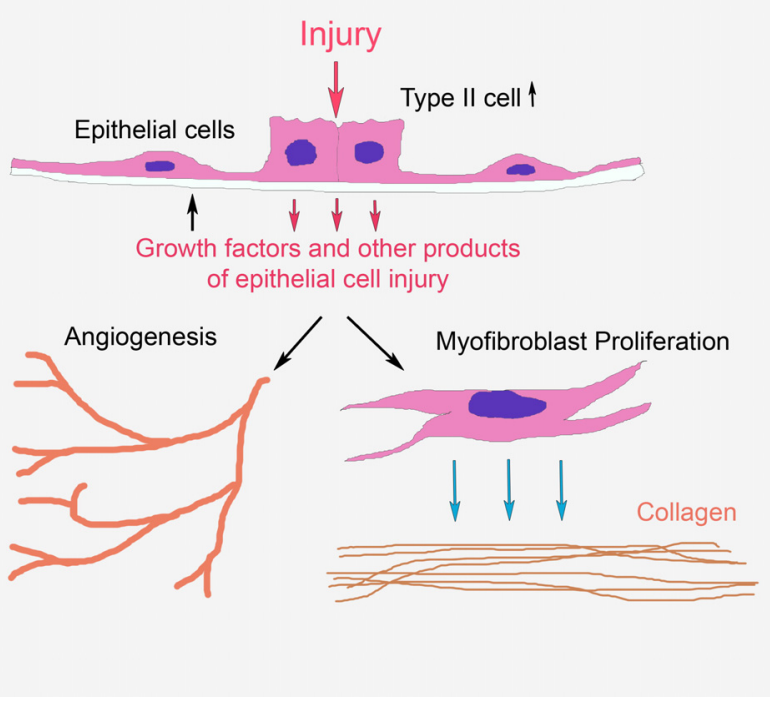

Fig. (2). Interaction between alveolar epithelial cells and mesenchymal cells.

damaged alveolar epithelium and by involving in the pathological process of fibrosis through the production of inflammatory cytokines and probably through transdifferentiation into myofibroblasts by the epithelial mesenchymal transition. Further defining the role of the AECs in pulmonary fibrosis is not only important for understanding the pathogenesis of pulmonary fibrosis but may also lead to the development of novel potential therapeutic targets.

\section{REFERENCES}

[1] Sloan JL, Grubb BR, Mager S. Expression of the amino acid transporter ATB 0+ in lung: possible role in luminal protein removal. Am J Physiol Lung Cell Mol Physiol 2003; 284(1): L39-49.

[2] Ridge KM, Olivera WG, Saldias F, et al. Alveolar type 1 cells express the alpha2 $\mathrm{Na}, \mathrm{K}$-ATPase, which contributes to lung liquid clearance. Circ Res 2003; 92(4): 453-60.

[3] Liebler JM, Borok Z, Li X, et al. Alveolar epithelial type I cells express beta2-adrenergic receptors and G-protein receptor kinase 2. J Histochem Cytochem 2004; 52(6): 759-67.

[4] Matthay MA, Folkesson HG, Clerici C. Lung epithelial fluid transport and the resolution of pulmonary edema. Physiol Rev 2002; 82(3): 569-600.

[5] McCormack FX, Whitsett JA. The pulmonary collectins, SP-A and SP-D, orchestrate innate immunity in the lung. J Clin Invest 2002; 109(6): 707-12.

[6] Sano H, Kuroki Y. The lung collectins, SP-A and SP-D, modulate pulmonary innate immunity. Mol Immunol 2005; 42(3): 279-87.

[7] Kapanci Y, Weibel ER, Kaplan HP, Robinson FR. Pathogenesis and reversibility of the pulmonary lesions of oxygen toxicity in monkeys. II. Ultrastructural and morphometric studies. Lab Invest 1969; 20(1): 101-18.

[8] Evans MJ, Cabral LJ, Stephens RJ, Freeman G. Transformation of alveolar type 2 cells to type 1 cells following exposure to $\mathrm{NO}_{2}$. Exp Mol Pathol 1975; 22(1): 142-50.

[9] Kotton DN, Ma BY, Cardoso WV, et al. Bone marrow-derived cells as progenitors of lung alveolar epithelium. Development 2001; 128(24): 5181-8.

[10] Abe S, Boyer C, Liu X, et al. Cells derived from the circulation contribute to the repair of lung injury. Am J Respir Crit Care Med 2004; 170(11): 1158-63.

[11] Shetty S, Padijnayayveetil J, Tucker T, Stankowska D, Idell S. The fibrinolytic system and the regulation of lung epithelial cell proteolysis, signaling, and cellular viability. Am J Physiol Lung Cell Mol Physiol 2008; 295(6): L967-75. 
[12] Shetty S, Idell S. Post-transcriptional regulation of urokinase mRNA. Identification of a novel urokinase mRNA-binding protein in human lung epithelial cells in vitro. J Biol Chem 2000; 275(18): 13771-9.

[13] Van Leer C, Stutz M, Haeberli A, Geiser T. Urokinase plasminogen activator released by alveolar epithelial cells modulates alveolar epithelial repair in vitro. Thromb Haemost 2005; 94(6): 125764.

[14] Reddy R, Buckley S, Doerken M, et al. Isolation of a putative progenitor subpopulation of alveolar epithelial type 2 cells. Am J Physiol Lung Cell Mol Physiol 2004; 286(4): L658-67.

[15] Pasternack M Jr, Liu X, Goodman RA, Rannels DE. Regulated stimulation of epithelial cell DNA synthesis by fibroblast-derived mediators. Am J Physiol 1997; 272(4 Pt 1): L619-30.

[16] Saffiotti U. Alveolar type II cells at the crossroad of inflammation, fibrogenesis, and neoplasia. Am J Pathol 1996; 149(5): 1423-6.

[17] Adamson IY, Hedgecock C, Bowden DH. Epithelial cell-fibroblast interactions in lung injury and repair. Am J Pathol 1990; 137(2): 385-92.

[18] Sime PJ, Xing Z, Graham FL, Csaky KG, Gauldie J. Adenovectormediated gene transfer of active transforming growth factor-betal induces prolonged severe fibrosis in rat lung. J Clin Invest 1997; 100(4): 768-76.

[19] Johansson J, Curstedt T, Robertson B. The proteins of the surfactant system. Eur Respir J 1994; 7(2): 372-91.

[20] Kasper M, Gunthert U, Dall P, et al. Distinct expression patterns of CD44 isoforms during human lung development and in pulmonary fibrosis. Am J Respir Cell Mol Biol 1995; 13(6): 648-56.

[21] Kasper M, Bierhaus A, Whyte A, Binns RM, Schuh D, Muller M. Expression of CD44 isoforms during bleomycin-or radiationinduced pulmonary fibrosis in rats and mini-pigs. Histochem Cell Biol 1996; 105(3): 221-30.

[22] Underhill CB, Nguyen HA, Shizari M, Culty M. CD44 positive macrophages take up hyaluronan during lung development. Dev Biol 1993; 155(2): 324-36.

[23] Driscoll KE, Howard BW, Carter JM, et al. Alpha-quartz-induced chemokine expression by rat lung epithelial cells: effects of in vivo and in vitro particle exposure. Am J Pathol 1996; 149(5): 1627-37.

[24] Crippen TL, Klasing KC, Hyde DM. Cytokine-induced neutrophil chemoattractant production by primary rat alveolar type II cells. Inflammation 1995; 19(5): 575-86.

[25] Cott GR, Westcott JY, Voelkel NF. Prostaglandin and leukotriene production by alveolar type II cells in vitro. Am J Physiol 1990; 258(4 Pt 1): L179-87.

[26] Lee CG, Cho SJ, Kang MJ, et al. Early growth response gene 1mediated apoptosis is essential for transforming growth factor beta1-induced pulmonary fibrosis. J Exp Med 2004; 200(3): 37789.

[27] Khalil N, O'Connor RN, Unruh $\mathrm{HW}$, et al. Increased production and immunohistochemical localization of transforming growth factor-beta in idiopathic pulmonary fibrosis. Am J Respir Cell Mol Biol 1991; 5(2): 155-62.

[28] Gurujeyalakshmi G, Hollinger MA, Giri SN. Regulation of transforming growth factor-beta1 mRNA expression by taurine and niacin in the bleomycin hamster model of lung fibrosis. Am J Respir Cell Mol Biol 1998; 18(3): 334-42.

[29] Wang Q, Wang Y, Hyde DM, et al. Reduction of bleomycin induced lung fibrosis by transforming growth factor beta soluble receptor in hamsters. Thorax 1999; 54(9): 805-12.

[30] Homma S, Nagaoka I, Abe H, et al. Localization of platelet-derived growth factor and insulin-like growth factor I in the fibrotic lung. Am J Respir Crit Care Med 1995; 152(6 Pt 1): 2084-9.

[31] Aston C, Jagirdar J, Lee TC, Hur T, Hintz RL, Rom WN. Enhanced insulin-like growth factor molecules in idiopathic pulmonary fibrosis. Am J Respir Crit Care Med 1995; 151(5): 1597-603.

[32] Antoniades HN, Bravo MA, Avila RE, et al. Platelet-derived growth factor in idiopathic pulmonary fibrosis. J Clin Invest 1990; 86(4): 1055-64.

[33] Jagirdar J, Begin R, Dufresne A, Goswami S, Lee TC, Rom WN. Transforming growth factor-beta (TGF-beta) in silicosis. Am J Respir Crit Care Med 1996; 154(4 Pt 1): 1076-81.

[34] Nash JR, McLaughlin PJ, Butcher D, Corrin B. Expression of tumour necrosis factor-alpha in cryptogenic fibrosing alveolitis. Histopathology 1993; 22(4): 343-7.

[35] Kumar NM, Rabadi NH, Sigurdson LS, Schunemann HJ, Lwebuga-Mukasa JS. Induction of interleukin-1 and interleukin-8
mRNAs and proteins by TGF beta 1 in rat lung alveolar epithelial cells. J Cell Physiol 1996; 169(1): 186-99.

[36] Ohtsuka Y, Munakata M, Ukita H, et al. Increased susceptibility to silicosis and TNF-alpha production in C57BL/6J mice. Am J Respir Crit Care Med 1995; 152 (6 Pt 1): 2144-9.

[37] Miyazaki Y, Araki K, Vesin C, et al. Expression of a tumor necrosis factor-alpha transgene in murine lung causes lymphocytic and fibrosing alveolitis. A mouse model of progressive pulmonary fibrosis. J Clin Invest 1995; 96(1): 250-9.

[38] Sakai T, Satoh K, Matsushima K, et al. Hepatocyte growth factor in bronchoalveolar lavage fluids and cells in patients with inflammatory chest diseases of the lower respiratory tract: detection by RIA and in situ hybridization. Am J Respir Cell Mol Biol 1997; 16(4): 388-97.

[39] Shukla MN, Rose JL, Ray R, Lathrop KL, Ray A, Ray P. Hepatocyte growth factor inhibits epithelial to myofibroblast transition in lung cells via Smad7. Am J Respir Cell Mol Biol 2009; 40(6): 64353.

[40] Coalson JJ. The ultrastructure of human fibrosing alveolitis. Virchows Arch A Pathol Anat Histol 1982; 395(2): 181-99.

[41] Lawson WE, Crossno PF, Polosukhin VV, et al. Endoplasmic reticulum stress in alveolar epithelial cells is prominent in IPF: association with altered surfactant protein processing and herpesvirus infection. Am J Physiol Lung Cell Mol Physiol 2008; 294(6): L1119-26.

[42] Korfei M, Ruppert C, Mahavadi P, et al. Epithelial endoplasmic reticulum stress and apoptosis in sporadic idiopathic pulmonary fibrosis. Am J Respir Crit Care Med 2008; 178(8): 838-46.

[43] Harrison JH Jr, Hoyt DG, Lazo JS. Acute pulmonary toxicity of bleomycin: DNA scission and matrix protein mRNA levels in bleomycin-sensitive and -resistant strains of mice. Mol Pharmacol 1989; 36(2): 231-8.

[44] Kuwano K, Kunitake R, Kawasaki M, et al. P21Waf1/Cip1/Sdi1 and p53 expression in association with DNA strand breaks in idiopathic pulmonary fibrosis. Am J Respir Crit Care Med 1996; 154(2 Pt 1): 477-83.

[45] Barbas-Filho JV, Ferreira MA, Sesso A, Kairalla RA, Carvalho CR, Capelozzi VL. Evidence of type II pneumocyte apoptosis in the pathogenesis of idiopathic pulmonary fibrosis (IFP)/usual interstitial pneumonia (UIP). J Clin Pathol 2001; 54(2): 132-8

[46] Kuwano K, Hagimoto N, Maeyama T, et al. Mitochondriamediated apoptosis of lung epithelial cells in idiopathic interstitial pneumonias. Lab Invest 2002; 82(12): 1695-706.

[47] Bardales RH, Xie SS, Schaefer RF, Hsu SM. Apoptosis is a major pathway responsible for the resolution of type II pneumocytes in acute lung injury. Am J Pathol 1996; 149(3): 845-52.

[48] Guinee D Jr, Brambilla E, Fleming M, et al. The potential role of BAX and BCL-2 expression in diffuse alveolar damage. Am J Pathol 1997; 151(4): 999-1007.

[49] Plataki M, Koutsopoulos AV, Darivianaki K, Delides G, Siafakas NM, Bouros D. Expression of apoptotic and antiapoptotic markers in epithelial cells in idiopathic pulmonary fibrosis. Chest 2005 ; 127(1): 266-74.

[50] Maeyama T, Kuwano K, Kawasaki M, et al. Upregulation of Fassignalling molecules in lung epithelial cells from patients with idiopathic pulmonary fibrosis. Eur Respir J 2001; 17(2): 180-9.

[51] Haimovitz-Friedman A, Cordon-Cardo C, Bayoumy S, et al. Lipopolysaccharide induces disseminated endothelial apoptosis requiring ceramide generation. J Exp Med 1997; 186(11): 1831-41.

[52] Kawasaki M, Kuwano K, Hagimoto N, et al. Protection from lethal apoptosis in lipopolysaccharide-induced acute lung injury in mice by a caspase inhibitor. Am J Pathol 2000; 157(2): 597-603.

[53] Maeyama T, Kuwano K, Kawasaki M, Kunitake R, Hagimoto N, Hara N. Attenuation of bleomycin-induced pneumopathy in mice by monoclonal antibody to interleukin-12. Am J Physiol Lung Cell Mol Physiol 2001; 280(6): L1128-37.

[54] Wang R, Ibarra-Sunga O, Verlinski L, Pick R, Uhal BD. Abrogation of bleomycin-induced epithelial apoptosis and lung fibrosis by captopril or by a caspase inhibitor. Am J Physiol Lung Cell Mol Physiol 2000; 279(1): L143-51.

[55] Uhal BD, Joshi I, Hughes WF, Ramos C, Pardo A, Selman M. Alveolar epithelial cell death adjacent to underlying myofibroblasts in advanced fibrotic human lung. Am J Physiol 1998; 275(6 Pt 1): L1192-9.

[56] Keogh BA, Crystal RG. Alveolitis: the key to the interstitial lung disorders. Thorax 1982; 37(1): 1-10. 
[57] Crystal RG, Bitterman PB, Mossman B, et al. Future research directions in idiopathic pulmonary fibrosis: summary of a National Heart, Lung, and Blood Institute working group. Am J Respir Crit Care Med 2002; 166(2): 236-46.

[58] Selman M, King TE, Pardo A. Idiopathic pulmonary fibrosis: prevailing and evolving hypotheses about its pathogenesis and implications for therapy. Ann Intern Med 2001; 134(2): 136-51.

[59] Thannickal VJ, Toews GB, White ES, Lynch JP 3rd, Martinez FJ. Mechanisms of pulmonary fibrosis. Annu Rev Med 2004; 55: 395417.

[60] Selman M, Pardo A. The epithelial/fibroblastic pathway in the pathogenesis of idiopathic pulmonary fibrosis. Am J Respir Cell Mol Biol 2003; 29(3 Suppl): S93-7.

[61] Witschi H, Haschek WM, Meyer KR, Ullrich RL, Dalbey WE. A pathogenetic mechanism in lung fibrosis. Chest 1980; 78(2 Suppl): 395-9.

[62] Katzenstein AL. Pathogenesis of "fibrosis" in interstitial pneumonia: an electron microscopic study. Hum Pathol 1985; 16(10): $1015-24$.
[63] Myers JL, Katzenstein AL. Epithelial necrosis and alveolar collapse in the pathogenesis of usual interstitial pneumonia. Chest 1988; 94(6): 1309-11.

[64] Chilosi M, Poletti V, Zamo A, et al. Aberrant Wnt/beta-catenin pathway activation in idiopathic pulmonary fibrosis. Am J Pathol 2003; 162(5): 1495-502.

[65] Willis BC, Liebler JM, Luby-Phelps K, et al. Induction of epithelial-mesenchymal transition in alveolar epithelial cells by transforming growth factor-beta1: potential role in idiopathic pulmonary fibrosis. Am J Pathol 2005; 166(5): 1321-32.

[66] Willis BC, Borok Z. TGF-beta-induced EMT: mechanisms and implications for fibrotic lung disease. Am J Physiol Lung Cell Mol Physiol 2007; 293(3): L525-34.

[67] Yao HW, Xie QM, Chen JQ, Deng YM, Tang HF. TGF-beta1 induces alveolar epithelial to mesenchymal transition in vitro. Life Sci 2004; 76(1): 29-37.

[68] Kasai H, Allen JT, Mason RM, Kamimura T, Zhang Z. TGF-beta1 induces human alveolar epithelial to mesenchymal cell transition (EMT). Respir Res 2005; 6: 56.

Received: May 25, 2009

Revised: July 01, 2009

Accepted: July 04, 2009

(C) Huiping Li; Licensee Bentham Open.

This is an open access article licensed under the terms of the Creative Commons Attribution Non-Commercial License (http://creativecommons.org/licenses/by-nc/3.0/) which permits unrestricted, non-commercial use, distribution and reproduction in any medium, provided the work is properly cited. 